\title{
Laser Cladding of 420 Stainless Steel with Molybdenum on Mild Steel A36 by a High Power Direct Diode Laser
}

\author{
Zhe Zhang, Parisa Farahmand, and Radovan Kovacevic* \\ Center for Laser-aided Manufacturing, Lyle School of Engineering, Southern Methodist University, 3101 \\ Dyer Street, Dallas, TX 75206, USA \\ *Corresponding author. Email: kovacevi@ smu.edu; Tel.: +1 214768 4865; Fax: +1 2147680812.
}

\begin{abstract}
Laser cladding, as one of the most promising surface modification technologies, is being widely applied in industry to improve the wear and corrosion resistance of components. The high energy input and high cooling rate during the cladding process lead to severe metallurgical reactions that determine the microstructure and properties of the cladded layer. In this study, a 3-dimensional (3-D) finite element (FE) model was developed to study heat transfer during laser cladding of 420 stainless steel+ $4 \%$ molybdenum on mild steel A36. In this model, the effects of laser-powder interaction, temperature-dependent material properties, latent heat, and Marangoni flow were considered. A method based on mass balance was adopted to predict the clad geometry. The thermal results such as the temperature history, temperature gradient, and solidification rate were investigated. Based on the simulated thermal results, the microstructure and Mo distribution in the clad layer were studied. In order to verify the established model, a series of experiments was conducted by using an 8-kW high-power direct diode laser (HPDDL). Thermocouples and a CCD camera were used to monitor the temperature history and molten pool size. The predicted clad height and width showed a good agreement with the experimental results.
\end{abstract}

Keywords laser cladding; numerical simulation, heat transfer, molybdenum 


\section{Introduction}

Laser cladding is an advanced technique used to improve component surface properties and functionality. Over the past several decades, laser cladding has been receiving greater acceptance by industry in contrast to conventional surface modification methods. This acceptance is due to the unique features of laser cladding, such as low dilution, fine grain size, good metallurgical bonding, and low distortion [1-2]. Recent development of the high power direct diode lasers (HPDDL) is opening new opportunities for localized material surface modifications [3]. HPDDL is characterized by high electrical efficiency, high absorption rate, and low maintenance cost [4]. Moreover, the top-hat distribution of the laser beam produces a more uniform microstructure with a smaller heat affected zone (HAZ) [5]. The rectangular beam size $(12 \mathrm{~mm} / 24 \mathrm{~mm} \times \mathrm{x} \mathrm{mm})$ also improves cladding efficiency.

AISI 420 is a widely used material in the oil and gas industry because of its toughness and strength. However, AISI 420 generally has poor corrosion resistance because its content has a low percentage of chromium and nickel. The refractory element Molybdenum can improve corrosion resistance, especially the localized corrosion resistance of stainless steel. However, the higher melting temperature of Mo $\left(2623{ }^{\circ} \mathrm{C}\right)$ makes it difficult for Mo to become fully melted. As a result, it is necessary to study heat transfer during the laser cladding process in order to enhance the melting status of Mo and achieve a uniform distribution in the clad. Moreover, the thermal history of the laser cladding process, including temperature evolution, temperature gradient, and cooling rates, is the main determining factor for the outcome of the coating microstructure and mechanical properties. During the cladding process, several effective parameters such as laser power, scanning speed, powder feed rate, stand-off distance, metal powder compositions, and shielding gas flow rate also strongly influence thermal history. In addition, the laser cladding process involves complex physical phenomena, such as laser-powder interaction, heat transfer, melting, solidification, and mass addition. This complex physical process cannot be studied only by experimentation. Numerical simulation gives us an efficient way to better understand the complexity of the physical process.

To date, a number of numerical models for the laser cladding process have been developed and studied by researchers. L. Costa et al. [6] proposed a 3D finite element (FE) model to study heat transfer during the laser powder deposition of a 10-layer steel wall. Based on the thermal results, a coupled kinetics model was developed to study microstructure and hardness of the consecutive layers. Soundarapandian et al. [7] developed an experimentally-based FE thermal model to predict the cross-section temperature history of the HPDDL cladding. The temperature gradient, heating rate, cooling cycles, and solidification rate were studied based on simulated temperature history. Farahmand et al. [8] established a 3D transient uncoupled thermo-elastic-plastic model to study the thermal process and thermally-induced residual stress in the HPDDL cladding. The calculated residual stress presented a good agreement with the experimental results. Toyserkani et al. [9-10] developed a 3D transient FE model to predict the laser cladding process by considering injected powder stream variables and corresponding laser power attenuation. In their model, the clad geometry was calculated according to mass balance by continuously stacking deposition materials in the molten pool. The thermo-capillary phenomenon in the molten pool was considered by modifying the thermal conductivity. A similar work was published by Vahid et al. [11]. Based on the clad geometry 
prediction strategy proposed by Toyserkani [9-10], the temporal development of the molten pool morphology and clad geometry in the laser powder deposition were simulated based on the element activation/deactivation technique by the commercial software ANSYS. The solid/liquid interface orientation, dendrite size variation, and clad dilution were investigated according to the simulated thermal results. P Peyre et al. [12] proposed a two-step method with a combination of analytical and numerical approaches to predict the geometry and thermal field during the direct metal deposition process. First, the steady state FE calculation and analytical calculation were combined to predict the geometry of the deposited layers. Then, to study the thermal process, a three-dimensional (3D) FE model was established based on the geometry data obtained in the first step. I. Tabernero et al. [13] developed a numerical model for the estimation of the clad height. The model contained three sub-models: the powder flow estimation, the prediction of molten pool geometry, and the interaction between laser beam and powder flow. The clad height and width were predicted based on mass balance. In particular, the injected powder mass and the mass of powder that was caught by the molten pool to generate the clad were considered.

In summary, several FE models for the laser cladding process have been proposed to study thermal history, metallurgical evolution, and stress distribution. To date, only a few authors have studied HPDDL cladding with a wide band laser beam [7-8]. In most of the studies about HPDDL cladding, the geometry of the cladding layer was predefined from the experimental data, and the effect of the powder stream on laser power attenuation was neglected. Moreover, the proposed laser-powder interaction models were established based on a circular beam with a coaxial nozzle or circular nozzles. The study on the interaction between the wide band laser and the rectangular outlet of the powder feeder is not widely published. In this study, a 3D FE model was proposed based on ANSYS software to study the heat transfer process in laser cladding of AISI 420 steel+4\% Mo on mild steel A36 by HPDDL. The laser powder interaction of off-axis HPDDL cladding was considered. The strategy of continuously stacking deposition materials into the molten pool area was adopted to predict the clad profile. The birth and death technique supported by ANSYS was used to simulate the additive nature of the cladding process. The clad shape, thermal gradient, and solidification rate with different scanning speeds were investigated. Then the distribution of Mo in the clad was discussed based on the simulation results. A series of experiments was carried out in order to verify the simulation results. Thermocouples and a high speed CCD camera were used to validate the thermal history and molten pool geometry. The predicted clad height and width were validated based on the cross-section micrographs of the clad layer.

\section{Experiment Setup}

An 8-kW direct diode laser with a wave length of $975 \mathrm{~nm}$ and a 6-axis KUKA robot were used for the laser cladding process (see Fig. 1(a)). Fig. 1(b) shows a schematic view of the laser cladding process. During the cladding process, the powder stream was injected into the processing area through two off-axis feeding nozzles installed symmetrically with respect to the laser head at an angle of $35^{\circ}$. The exit of the nozzle had a rectangular cross section with a dimension of $10 \mathrm{~mm} \times 1 \mathrm{~mm}$. Argon was used as a shielding gas during cladding to protect the molten pool from oxidization. A high speed CCD camera assisted by a green laser as an additional illumination source were used to monitor the molten pool evolution. The 
chromel-alumel (K-type) thermocouples were used to measure the thermal history during the cladding process. The installed positions of thermocouples are shown in Fig. 1(b). The selected cladding process parameters in this study are shown in Table 1.
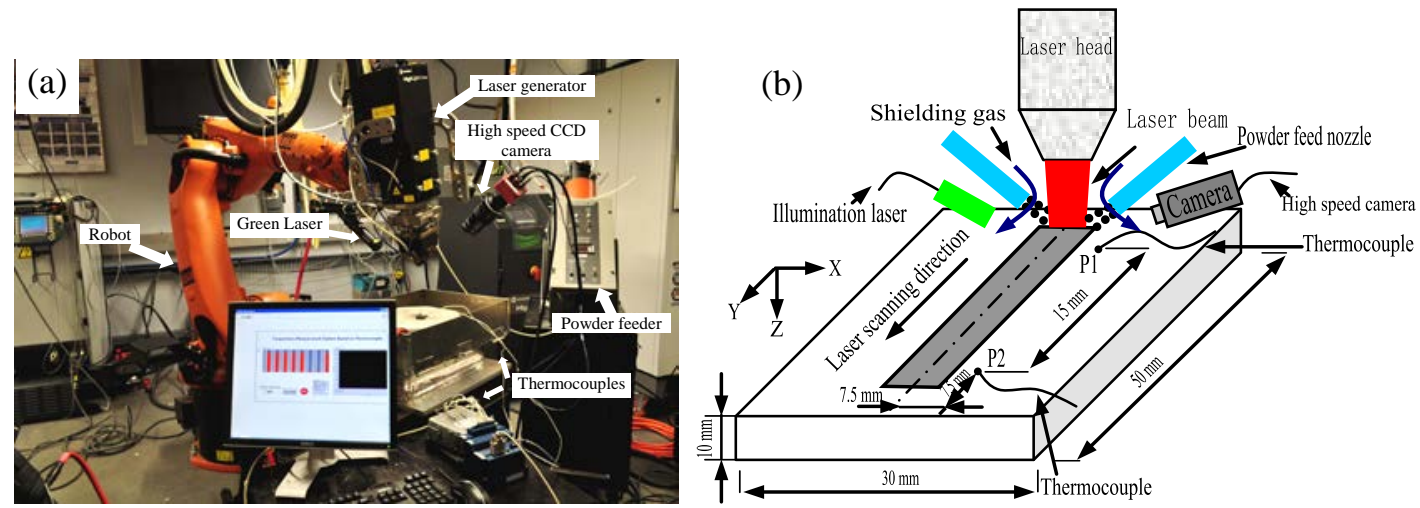

Fig. 1 Experimental setup, (a) overall experimental setup, (b) schematic of laser cladding process

Table 1 Process parameter for laser cladding process

\begin{tabular}{cccccc}
\hline Exp. No. & $\begin{array}{c}\text { Laser power } \\
\mathrm{W}\end{array}$ & $\begin{array}{c}\text { Scanning speed } \\
\mathrm{mm} / \mathrm{s}\end{array}$ & $\begin{array}{c}\text { Powder feeder rate } \\
\mathrm{g} / \mathrm{s}\end{array}$ & $\begin{array}{c}\text { Carrier gas (Ar) } \\
\mathrm{CFH}\end{array}$ & $\begin{array}{c}\text { Shielding gas (Ar) } \\
\mathrm{Pa}\end{array}$ \\
\hline 1 & 4100 & 3 & 0.43 & 20 & 60 \\
2 & 4100 & 4 & 0.43 & 20 & 60 \\
3 & 4100 & 5 & 0.43 & 20 & 60 \\
4 & 4100 & 6 & 0.43 & 20 & 60 \\
5 & 4100 & 7 & 0.43 & 20 & 60 \\
\hline
\end{tabular}

The plates of mild steel A36 with a dimension of $50 \times 30 \times 10 \mathrm{~mm}$ are used as the substrate (see Fig. 1(b)). The commercial AISI 420 powder sizes used in this study were between $53 \mu \mathrm{m}$ and $105 \mu \mathrm{m}$. The Mo particle sizes were between $15 \mu \mathrm{m}$ and $45 \mu \mathrm{m}$. Before the experiment was performed, the commercial AISI 420 powder was dried in the furnace to remove moisture. Then the powder was mixed with Mo in a ball shaker for $12 \mathrm{hr}$ to achieve a uniform distribution.

An optical microscope and scanning electron microscope (SEM) with energy dispersive spectroscopy (EDS) were used to study the microstructure. The specimens were sectioned by the abrasive water-jet cutting machine and mounted for grinding. The mounted specimens were ground with sand paper up to 1500 mesh and polished with $3 \mu \mathrm{m}$ and $1 \mu \mathrm{m}$ of diamond liquid, respectively. The Vilella solution $(2 \mathrm{~g}$ picric, $5 \mathrm{ml} \mathrm{HCl}$, and $100 \mathrm{ml}$ ethanol) was used to etch the specimens in order to reveal the microstructure.

\section{Laser-Powder Interactions}

The laser power is attenuated before it reaches the substrate due to its reflection and absorption by the powder. Meanwhile, the powder is heated up to a specific temperature before it is blown into the molten pool. In this work, the analytical model proposed by Pinkerton et al. [14] was further modified to study the laser-powder interaction between a wide band laser and powders injected from the rectangular nozzle.

The schematic diagram of the laser beam and powder streams is shown in Fig. 2. The powder streams are assumed to originate from the source points and merged with each other at the focus plane with a standoff distance of $11.00 \mathrm{~mm}$. The laser beam is rectangular with a top-hat distribution (see Fig. 3). At the 
focal plane, the size of the beam is $12 \mathrm{~mm} \times 3 \mathrm{~mm}$. The power distribution of the laser beam is expressed as [15],

Where $\eta=0.75$ is the laser absorption efficiency [7]. $P$ is laser power, and $w$ and $L$ are the width and length of the laser beam with the dimensions of $12 \mathrm{~mm}$ and $3 \mathrm{~mm}$, respectively.

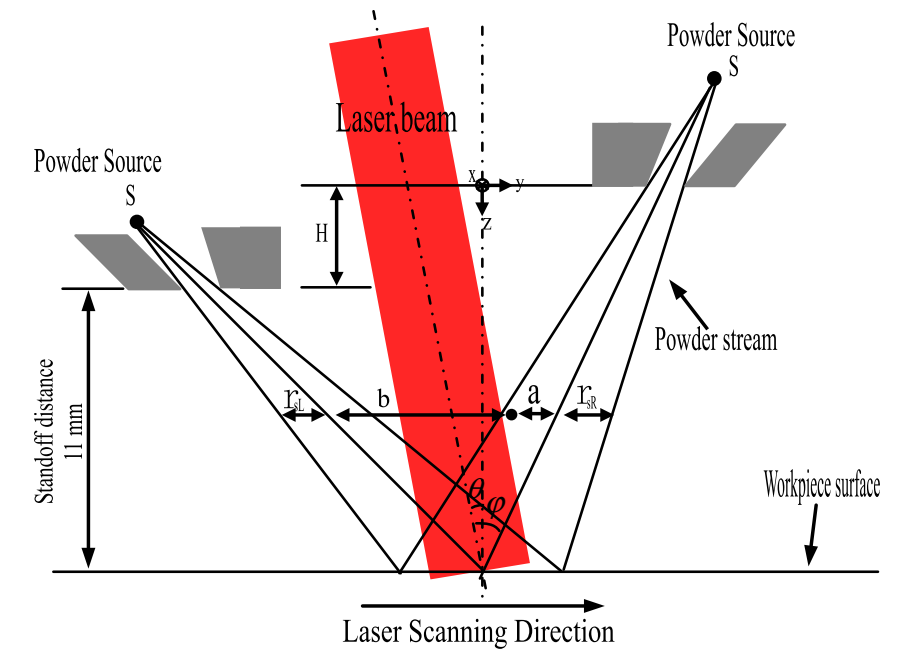

Fig. 2 The schematic diagram of the laser beam and powder streams

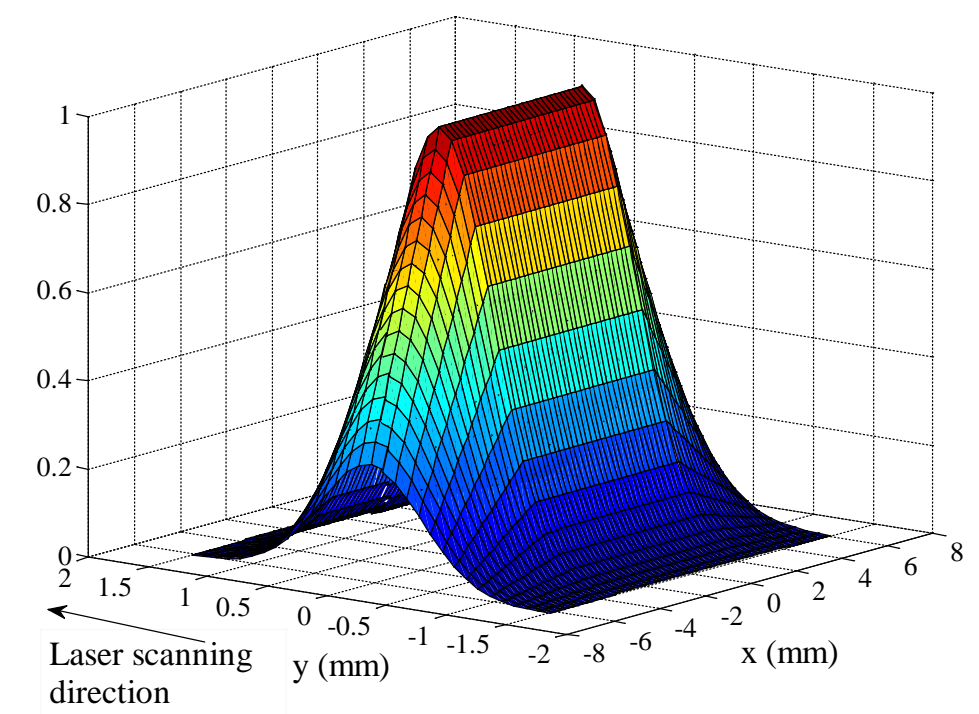

Fig. 3 Schematic view of the top-hat powder distribution

$$
I(x, y, z, t)=\left\{\begin{array}{l}
\eta \frac{P}{w \times L}\left(-\frac{6\left(y-y_{c}\right)^{2}}{d^{2}}\right) \text { for } \quad|x| \leq 0.26 w \\
\eta \frac{P}{w \times L}\left(-\frac{6\left(y-y_{c}\right)^{2}}{d^{2}}\right)\left(0.3+\frac{1-0.3}{0.24 w}(0.5 w-|x|)\right) \text { for } \quad 0.26 w \leq|x| \\
0 \quad \text { for } \quad|x| \geq 0.5 w
\end{array}\right.
$$

The calculation of powder attenuation was based on the shadow effect where the attenuation was proportional to the area of the particles projected into the beam [14]. The convection and radiation of powder streams during heating were negligible. According to Ref. [16], the powder concentration was 
considered as a Gaussian distribution in the yz-plane and uniform distribution in the xz-plane. Therefore, the powder flux $\mathrm{C}\left(\mathrm{kg} /\left(\mathrm{m}^{2} \mathrm{~s}\right)\right)$ at any position for left and right powder streams is expressed as Eq. (2) [14],

$$
\begin{gathered}
C_{R}=C_{m R} \exp \left(-\frac{2 a^{2}}{r_{s R}^{2}}\right) \\
C_{L}=C_{m L} \exp \left(-\frac{2 b^{2}}{r_{s L}^{2}}\right)
\end{gathered}
$$

Where $r_{s L}$ and $r_{s R}(\mathrm{~mm})$ are the half widths of the left and right powder streams at any z position. $a$ and $b(\mathrm{~mm})$ represent the distance from any point in the YZ-plane to the centerline of the right and left powder streams, respectively. $r_{s L}, r_{s R}, a$, and $b$ for a specific power particle are shown in Fig. 1. The equations for calculating $r_{s L}, r_{s R}, a$ and $b$ can be found in Ref. [14]. $C_{m R}$ and $C_{m L}$ are the maximum powder concentrations at the center of the right and left streams respectively. $C_{m R}$ and $C_{m L}$ are determined from the powder feed rates as follows,

$$
\begin{aligned}
& \frac{1}{2} m^{\prime}=w_{p} \int_{-r_{s R}}^{r_{s R}}\left[C_{m R} \exp \left(-\frac{2 a^{2}}{r_{s R}^{2}}\right)\right] d a \\
& \frac{1}{2} m^{\prime}=w_{p} \int_{-r_{s L}}^{r_{s L}}\left[C_{m L} \exp \left(-\frac{2 b^{2}}{r_{s L}^{2}}\right)\right] d b
\end{aligned}
$$

Where $m^{\prime}(\mathrm{kg} / \mathrm{s})$ is the powder feed rate. $w_{p}(\mathrm{~m})$ is the width of the powder beam in the $\mathrm{x}$ direction.

Thus, by considering the shadow effect, the laser intensity at any position after powder attenuation can be computed with the following equation [14],

$$
I_{\text {attenuation }}(x, y, z)=I(x, y, z)\left[1-\pi r_{p}^{2}\left(\frac{3}{4 \pi r_{p}^{3} \rho v_{p z R}}\right) \int_{0}^{z} C_{R}(z) d z-\pi r_{p}^{2}\left(\frac{3}{4 \pi r_{p}^{3} \rho v_{p z L}}\right) \int_{H}^{z} C_{L}(z) d z\right]
$$

Where $r_{p}$ is the radius of the powder particle, $\rho$ is the density of the powder particle, and $v_{p z R}$ and $v_{p z L}(\mathrm{~m} / \mathrm{s})$ are the powder particle velocity components in the $\mathrm{z}$ direction of the left and right powder streams. According to Ref. [16], the powder particle velocity was assumed to be $4.5 \mathrm{~m} / \mathrm{s}$ based on the selected processing parameters. The mean particle diameter of $79 \mu \mathrm{m}$ was used during the computation.

The increase in a particle temperature can be calculated according to Eq. (5) [14],

$$
\alpha I(x, y, z) \pi r_{p}^{2} \frac{\Delta z}{v_{p z}}=\frac{4 \pi r_{p}^{3}}{3} \rho c \Delta T
$$

Where $\alpha$ is the absorption coefficient of powder particles. $c$ is the specific heat of the powder particle. $\Delta z$ is the displacement change of powder in the z direction. $\Delta T$ is the temperature change of the powder. By integrating Eq. (5), the particle streams at any location (x, y, z) can be calculated as, 


$$
T(x, y, z)=T_{0}+\frac{3 \alpha}{4 \rho c r_{p}}\left[\frac{P_{A}}{v_{p z R}^{\prime}} \int_{0}^{z} I(x, y, z) d z+\frac{P_{B}}{v_{p z L}^{\prime}} \int_{H}^{z} I(x, y, z) d z\right]
$$

Where $v_{p z R}^{\prime}$ and $v_{p z L}^{\prime}$ are the particle velocity components along the $\mathrm{z}$ direction based on different particle paths. $P_{A}$ and $P_{B}$ are the proportions of powder obtained from the right and left powder beams and can be calculated by using the equations given in Ref. [14].

The calculated laser power attenuation at the focus plane is shown in Fig. 4. It can be seen from Fig. 4 that the laser attenuation is unsymmetrical due to the tilted laser head. At the focal plane, a weak power attenuation with the value of $0.98 \%-1.21 \%$ was achieved. As inferred from Eqs. (2) through (4), the power attenuation is related to the powder flux. The cross section of the nozzle in this study is a rectangular shape with a dimension of $10 \mathrm{~mm} \times 1 \mathrm{~mm}$. This nozzle is much larger than the off-axial circle or coaxial nozzles. Therefore, the powder flux was relatively sparse and, consequently resulted in a lower laser power attenuation. The powder temperature distribution at the focal plane is shown in Fig. 5. Similar to the laser intensity distribution, the powder temperature has a top-hat distribution at the focal plane. The maximum powder temperature is $172.1{ }^{\circ} \mathrm{C}$ at the center, while the minimum value is only $62.3{ }^{\circ} \mathrm{C}$ at the boundary. The calculated powder temperature demonstrated that the particles remained in a solid state before they were injected into the molten pool.

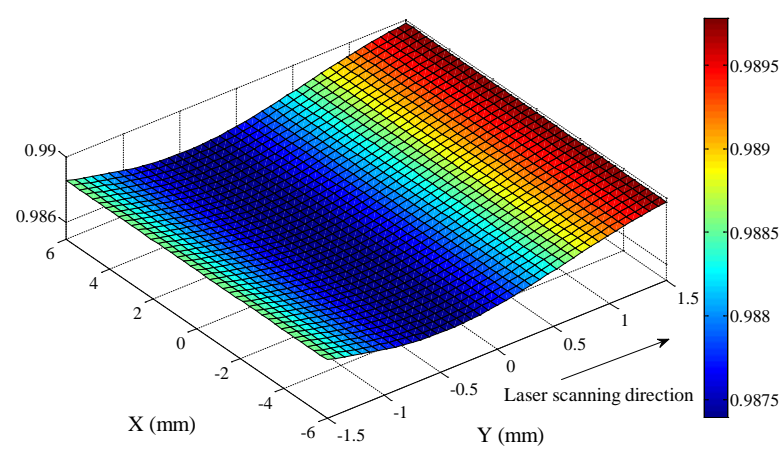

Fig. 4 Laser power attenuation distribution at the focal plane

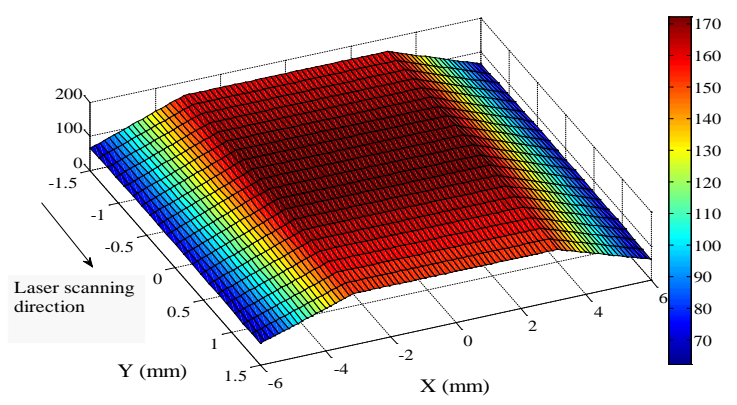

Fig. 5 Powder temperature distribution at the focal plane (laser power $4100 \mathrm{~W}$, carrier gas 20 $\mathrm{SCFH}$, and powder feed rate $0.43 \mathrm{~g} / \mathrm{s}$ )

\section{$4 \quad$ Finite Element Modeling}

\subsection{Governing Equations}

The transient process in the processing area can be described by the energy conservation equation as 
follows:

$$
\frac{\partial\left(\rho(T) C_{P}(\mathrm{~T}) T\right)}{\partial t}=\frac{\partial^{2}(k(T) T)}{\partial x^{2}}+\frac{\partial^{2}(k(T) T)}{\partial y^{2}}+\frac{\partial^{2}(k(T) T)}{\partial z^{2}}
$$

where $\rho$ is density, $\left(\mathrm{kg} / \mathrm{m}^{3}\right), C_{P}$ is specific heat capacity, $(\mathrm{J} / \mathrm{kgK})$, and $k$ is the thermal conductivity, $\left(W / m^{2} K\right)$.

The initial conditions both for the substrate and the powder are described by Eq. (8),

$$
T(x, y, z, t=0)=T_{\text {initial }}
$$

Where $T_{\text {initial }}$ is the initial temperature of the substrate and the powder.

On the boundaries, the heat gains and losses depend on the heat input from the laser beam, convection and radiation. The essential boundary conditions are described as Eq. (9),

$$
\left.k(\nabla T . \vec{n})\right|_{\Omega}= \begin{cases}h_{l}\left(T-T_{0}\right)-q & \Omega \in \Gamma \\ h_{l}\left(T-T_{0}\right) & \Omega \notin \Gamma\end{cases}
$$

Where $\vec{n}$ is the normal vector at the surface, $T_{0}$ is the room temperature, $\Omega$ is the surface of the substrate, and $\Gamma$ is the substrate surface exposed to the laser irradiation and shielding gas. In order to avoid nonlinearity and to simplify the calculation, a lumped heat transfer coefficient considering convention and radiation was adopted. The calculation of the lumped coefficient is expressed by Eq. (10) [17]. Where $q$ is the term related to the laser intensity defined by Eq. (11) [18].

$$
h_{l}=24.1 \times 10^{-4} \varepsilon T^{1.61}
$$

Where $\varepsilon$ is the emissivity of the substrate material with a value of 0.3 [19].

$$
q=I_{\text {attenuation }}+q_{\text {powder }}
$$

Where $I_{\text {attenuation }}$ is the laser power after powder attenuation, and $q_{\text {powder }}$ is the energy brought into the molten pool by the powder. $q_{\text {powder }}$ is calculated by Eq.(12) [14].

$$
q_{\text {powder }}=c_{p} \rho_{p} \Delta T_{P}
$$

Where $c_{p}, \rho_{p} \Delta T_{P}$ are the powder specific heat, powder density, and powder-temperature increment, respectively.

\subsection{Material Properties}

Material properties play a significant role in the accurate prediction of the numerical results. Therefore, the following adjustments were made on the material properties to result in a more realistic FE model.

(1) The material properties of substrate (A36) and cladded layers (96\% 420 stainless steel $+4 \%$ Mo) were considered to be temperature dependent (see Fig. 6). The temperature dependent material properties of A36 and Mo were obtained from Refs. [20-21]. The temperature dependent material properties of AISI 420 were obtained from the database of the commercial software SYSWELD [22].

(2) The effect of the latent heat of fusion on the temperature distribution was considered by modifying 
the specific heat capacity $C_{P}$ [23].

$$
C_{p}^{m}=\frac{L_{f}}{T_{m}-T_{0}}+C_{p}
$$

Where $L_{f}$ is the latent heat of fusion. The value of $L_{f}$ for AISI420 and A36 is $250 \mathrm{~kJ} / \mathrm{kg}$ and 277 $\mathrm{kJ} / \mathrm{kg}$, respectively $[6,24] . T_{m}$ is the melting point of the materials. The values of $T_{m}$ for AISI 420 and A36 are taken as $1450{ }^{\circ} \mathrm{C}$ and $1480{ }^{\circ} \mathrm{C}$, respectively. $C_{P}$ is the specific heat at the melting point. $T_{0}$ is the room temperature $\left(25^{\circ} \mathrm{C}\right)$.

(3) The effect of fluid motion due to the thermo-capillary phenomenon, namely Marangoni flow, was considered by modifying the thermal conductivity [25]. The modification is described as,

$$
k_{i}^{*}=m_{i} k_{i}(T) \quad \text { if } \quad T \geq T_{m}
$$

Where $m_{i}$ is the enhanced conductivity factor. The value subscript is equal to 1,2 , and 3 , corresponding to the $\mathrm{x}, \mathrm{y}$, and $\mathrm{z}$ axes in the Cartesian coordinate system. The selection of the value $m$ is based on trial and error [26], and the values of 5,10, and 1 were selected in this study for the laser scanning direction, the direction perpendicular to the laser scanning, and the thickness direction, respectively.

(4) The material properties of elements in the cladded layers were randomly allocated based on the $4 \%$ mass fraction of the added Mo powders.
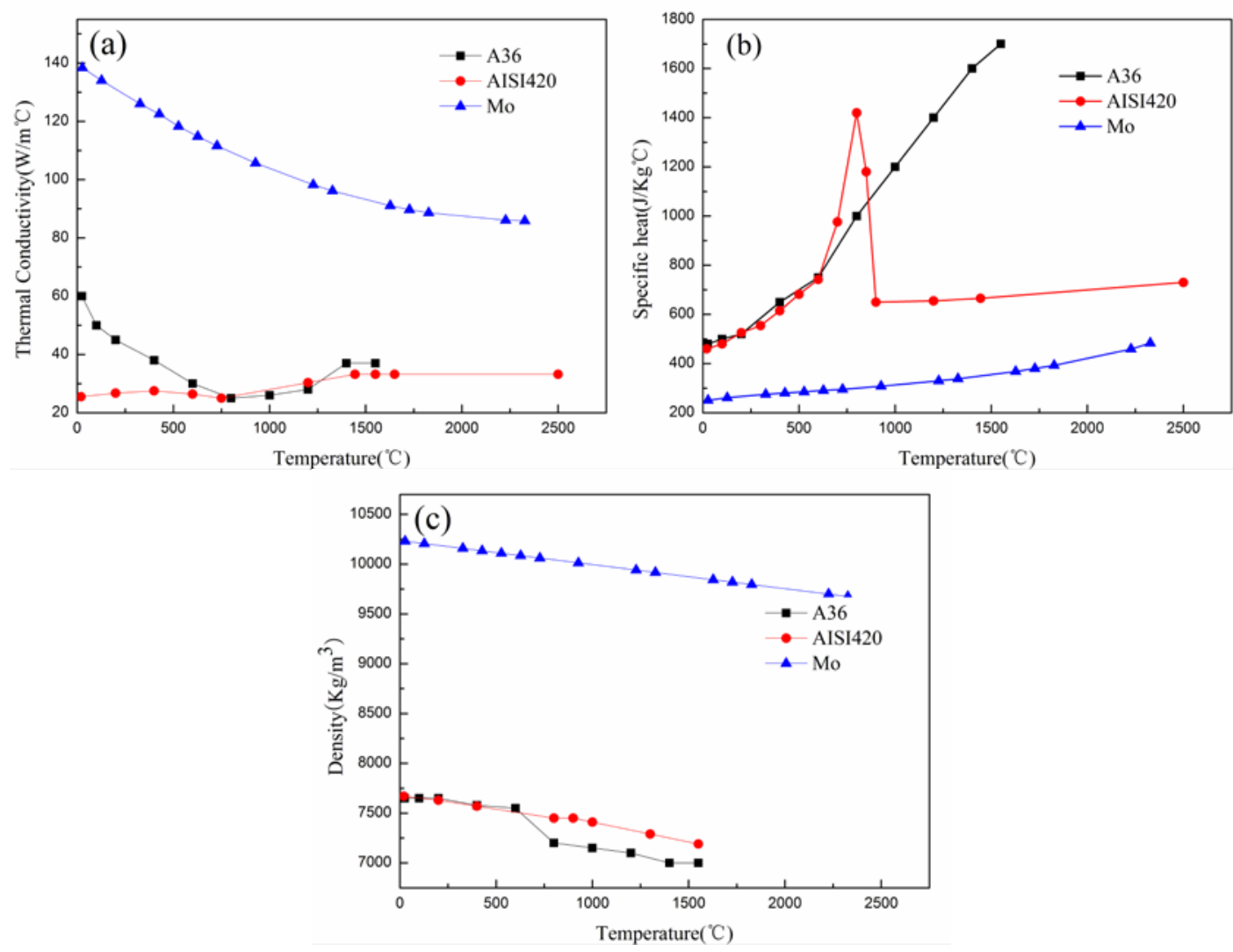

Fig. 6 Temperature dependent material properties, (a) Thermal conductivity, (b) Specific heat, (c) Density 


\subsection{Modeling of cladding procedure}

The element stacking method proposed in Refs. $[9,10]$ was used in this study to simulate the process of adding powder into the molten pool and to predict the clad profile. The schematic view of the stacking element procedure is shown in Fig. 7.

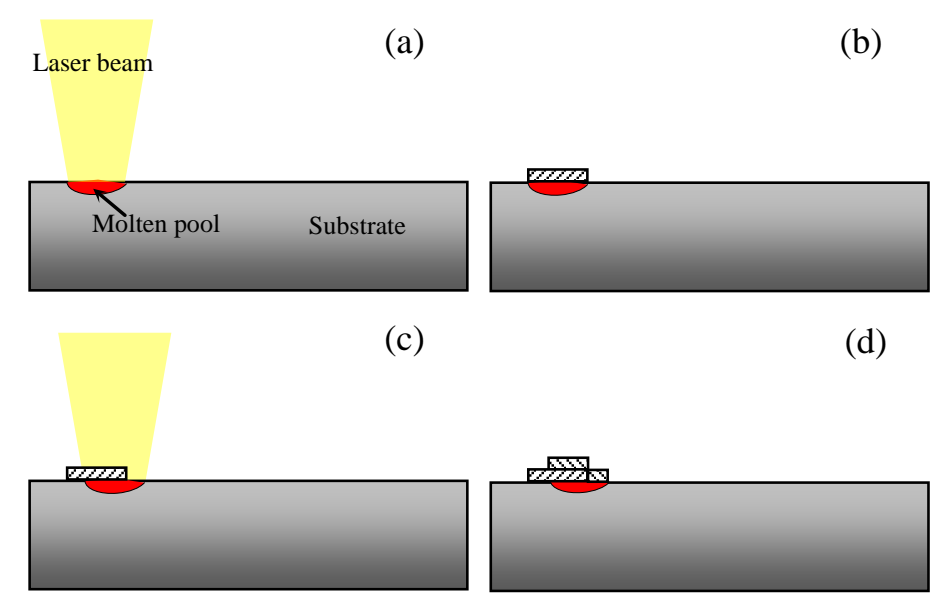

Fig. 7 Schematic solution strategy

After the laser irradiation, a molten pool forms on the surface of the substrate (see Fig. 7(a)). Then, a thin layer of molten powder is added at the interaction area between the molten pool and powder stream (see Fig. 7(b)). Next, based on the solution time step and laser scanning speed, the laser beam is moved to the next position. With the updated geometry and updated position of the laser beam, a new molten pool forms on the substrate (see Fig. 7(c)). Then, a new layer of powder is added. By repeating this procedure, the additive nature of cladding is imitated, and the geometry of the cladded layer is formed. The thickness of the added thin layer is calculated based on Eq. (15) [11].

$$
h=\frac{m^{\prime} \beta \Delta t}{\rho\left(w L+w^{*} V \Delta t\right)}
$$

Where $m^{\prime}$ is the powder feed rate, $\beta$ is the powder catchment efficiency, $\Delta t$ is the simulation time step, $w$ and $L$ are the width and length of the laser beam, and $V$ is the scanning speed.

\subsection{Model Geometry and Mesh}

The 3D FE model based on the experimental geometry is shown in Fig. 8. Only half of the model was established by considering the symmetry along the laser scanning direction. In order to achieve high calculation accuracy and decrease the computational time, a non-uniform mesh was adopted. The finer mesh was used in the molten pool, and the courser mesh was generated in the substrate and HAZ. Based on the powder composition, $4 \%$ of the elements in the cladded layer were randomly selected and attributed to the properties of Molybdenum (black color elements). The white elements in the cladded layer represent 420 steel (see Fig. 8 (b)). 

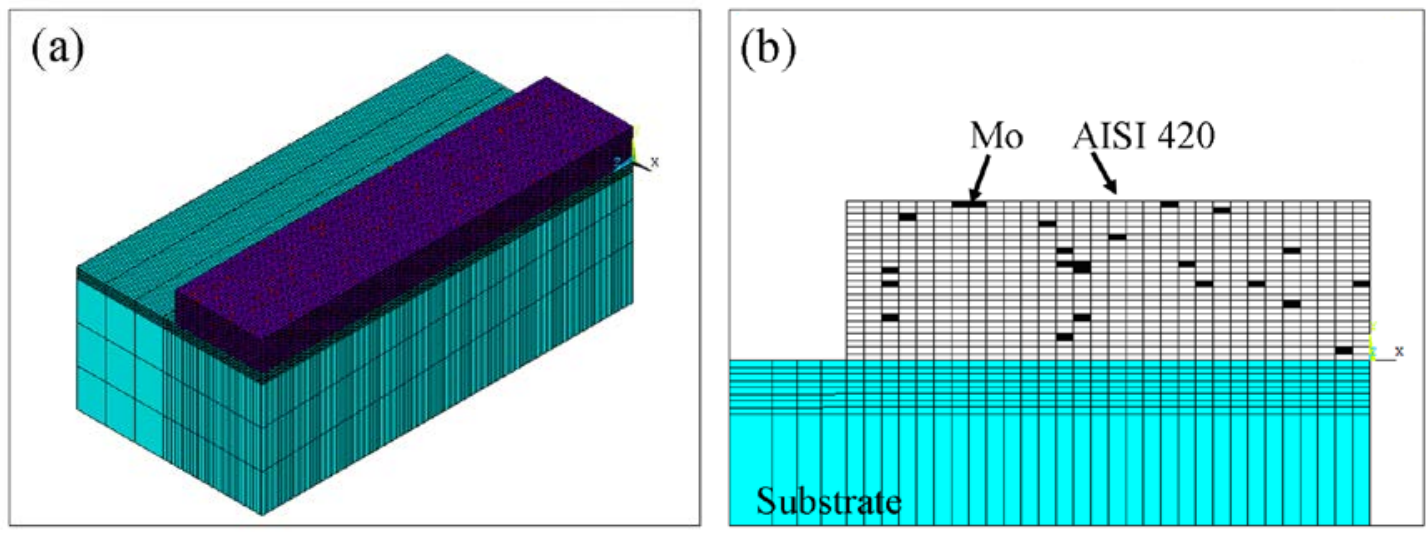

Fig. 8 Finite element mesh model, (a) General view; (b) Cross-sectional view

\section{$5 \quad$ Results and Discussion}

\subsection{Simulation Results Validation}

The geometry and thermal behavior of the molten pool are significant to the final quality of the clads. The solidification process and final microstructure are decided by the cooling rate at the solid/liquid interface. Moreover, the clad geometry depends on the molten pool size and the amounts of the powder caught by the molten pool [27]. Fig. 9 compares the numerically and experimentally obtained molten pools during the cladding process. As shown in Fig. 9(a), the front of the molten pool exhibits a sloped shape due to the surface tension between the solidified clad bead and the liquid metal powder. Fig. 9(b) illustrates the simulated molten pool shape at $8.5 \mathrm{~s}$. The marked area in Fig. 9(b) represents the molten pool where the temperature is higher than the melting point of the AISI $420\left(1450{ }^{\circ} \mathrm{C}\right)$. As inferred from Fig. 9 (b), the additive nature of laser cladding is simulated well by the birth and death element technique. The newly deposited material has a sloped shape (see Fig 9(a)) that is well simulated by the element stacking method.
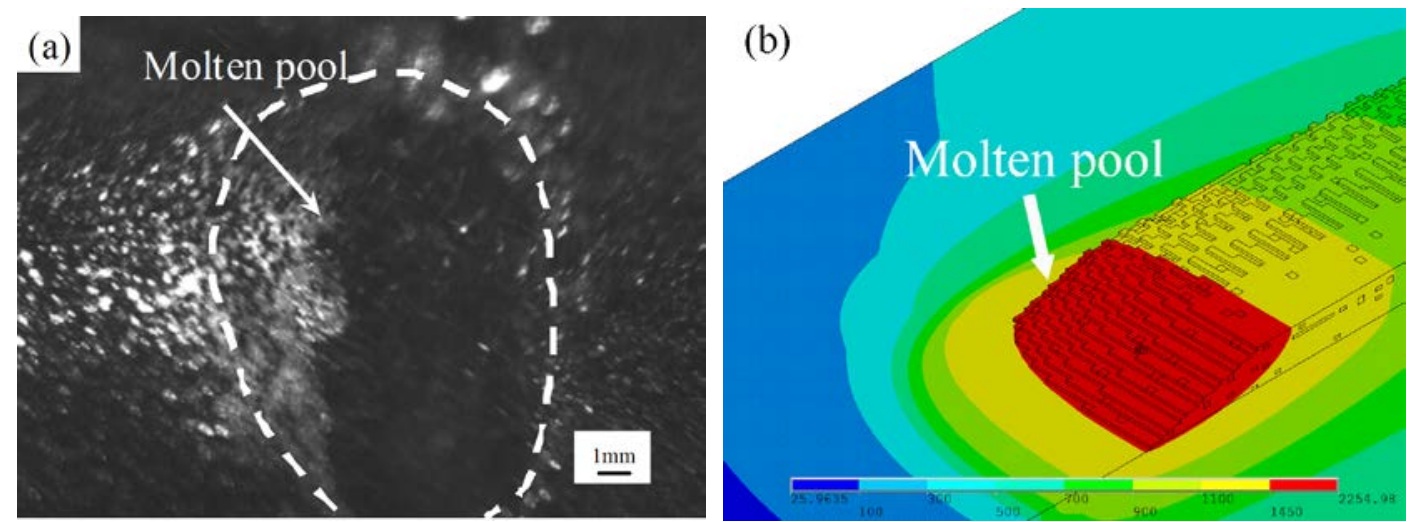

Fig. 9 the molten pool shape (Experiment No. 1), (a) CCD camera image,

(b) Simulated molten pool shape at $8.5 \mathrm{~s}$

Fig. 10 compares the numerical and experimental clad cross sections. As seen from Fig. 10, the general geometry of the cross section is well presented. However, the prediction of the curved surface of the cladded layer does not fit very well with the experimental one, especially at the boundary of the cladded layer. This could be attributed to two reasons. First, the size of the mesh was not fine enough to capture the geometrical changes at the boundary of the molten pool due to the limitations of the software and the 
computational capacity of the computer. Second, based on the solution strategy, a uniform layer was activated during each solution time step. This condition did not occur in the actual cladding.

The comparison between the experimental and simulation results of the height and width of the cladded layer with different processing parameters is shown in Fig. 11. As shown in this figure, the clad height and width both decrease with the increase in scanning speed. The increase in scanning speed led to the decrease in energy input due to the decrease in the interaction time between the laser beam and substrate. As a result, the molten pool size shrank and the powder catchment efficiency was reduced. Through the comparison between the experimental and simulation results in Fig. 11, it can be concluded that the numerical results match well with the experimental ones. The error of the predicted width is between $1 \%$ and $8 \%$ and the error of the predicted height is between $1 \%$ and $10 \%$. These predicted errors are in an acceptable range of tolerance for the laser cladding process based on HPDDL.

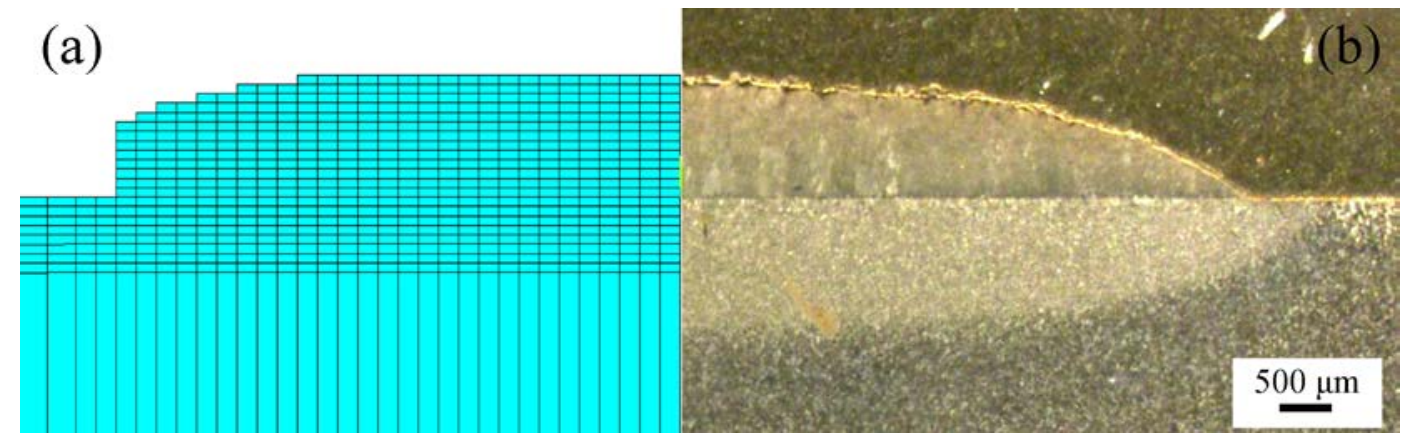

Fig. 10 Cross-section comparison between (a) simulation results, and (b) experimental results (Experiment No. 1)
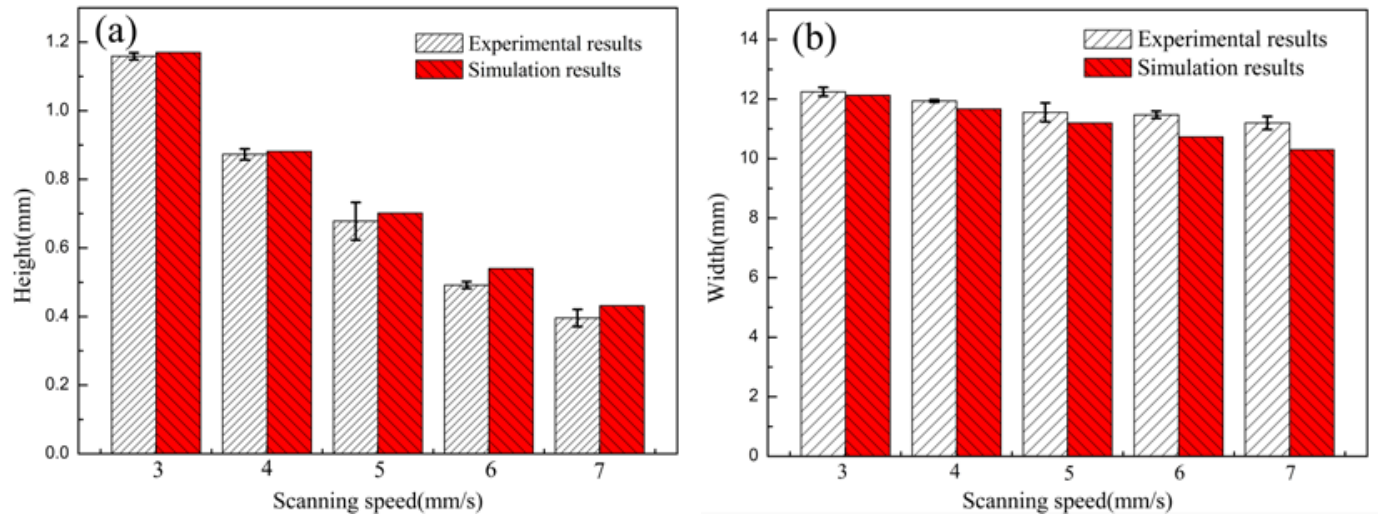

Fig. 11 Comparison of cladding geometry between numerical and experimental results, (a)

\section{Height, (b) Width}

Fig. 12 presents the comparison of the experimentally obtained and simulated temperature histories at two different marked points under a laser power of $4100 \mathrm{~W}$ and a scanning speed of $3 \mathrm{~mm} / \mathrm{s}$. As illustrated in Fig. 12, the peak temperature of $\mathrm{P} 2$ is higher than that of $\mathrm{P} 1$, which can be attributed to the heat accumulation during the cladding process. Through comparison, it can be concluded that good correlations are achieved for the peak temperatures and cooling rates of the experimental and simulation results. 


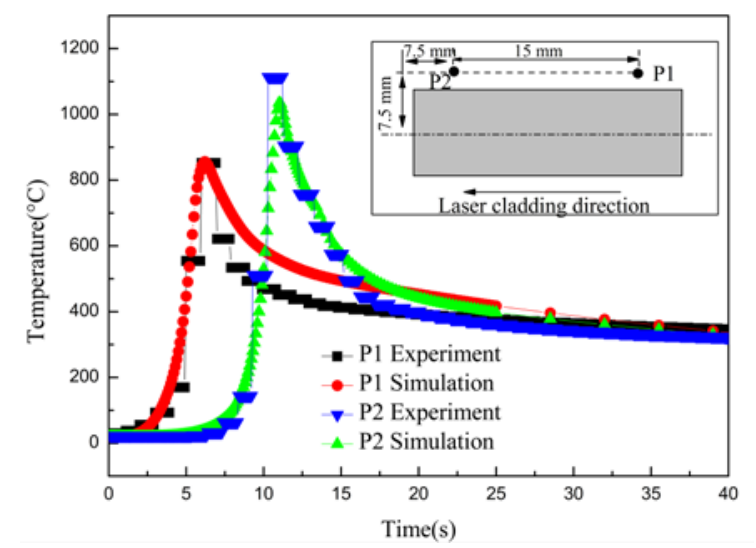

Fig. 12 Comparison between experimental and numerical temperature evolution (Experiment

No. 1)

\subsection{Temperature Field Evolution}

The temperature field evolution during cladding is shown in Fig. 13 in the six time steps. As shown in Fig. 13(a), the geometry of the cladded layer is not stable at the beginning. At the initial stage of the cladding, the heat received by the substrate from the laser beam and the heat losses due to the convection and conduction were not in balance. Therefore, the geometry of the molten pool was not stable, and led consequently to an unstable clad geometry. With the laser beam moving forward, the temperature field became stable and uniform. The maximum peak temperature during the cladding process could reach $2240{ }^{\circ} \mathrm{C}$, demonstrating that a large amount of heat input was absorbed by the substrate. Moreover, as illustrated in Fig. 13(a-d), the temperature changes sharply at the vicinity of the molten pool, indicating the existence of a high temperature gradient in these regions.
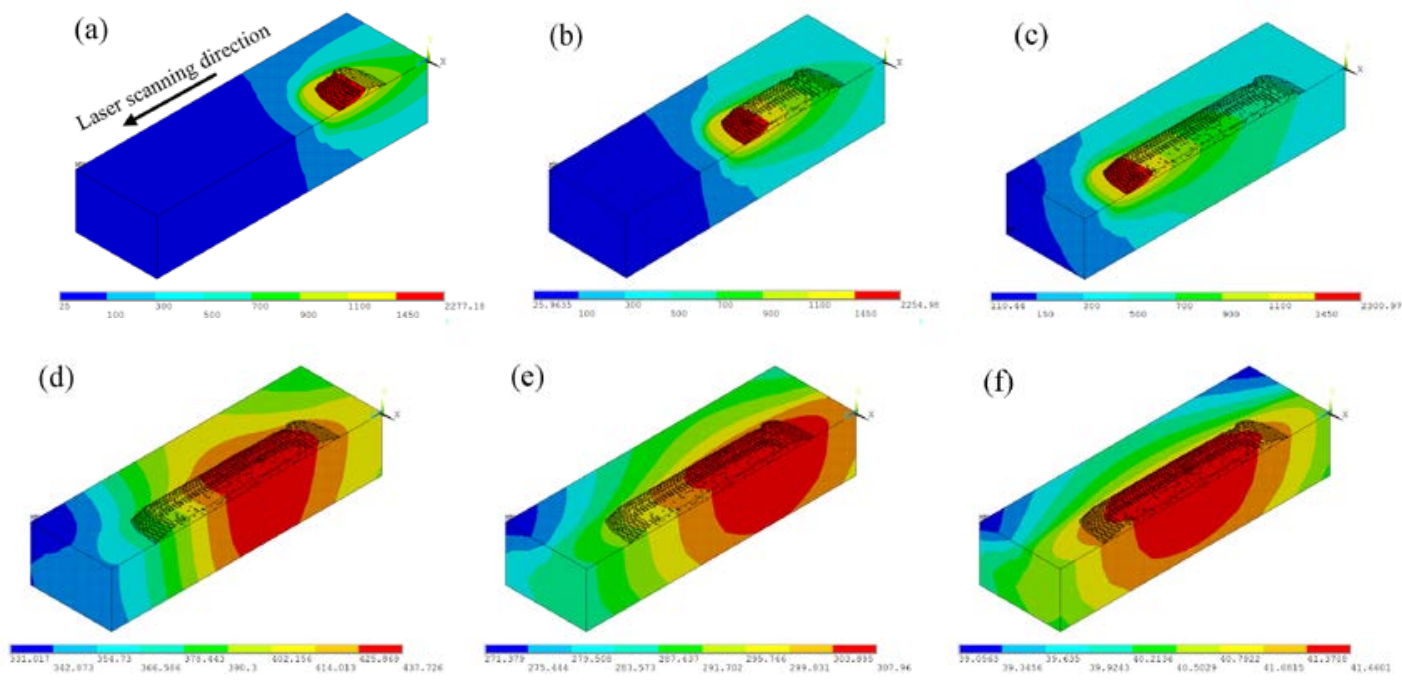

Fig. 13 Temperature evolution with $4100 \mathrm{~W}$ and $3 \mathrm{~mm} / \mathrm{s}$ (a) $4.9 \mathrm{~s}$, (b) $8.4 \mathrm{~s}$, (c) $13.4 \mathrm{~s}$, (d) $25 \mathrm{~s}$, (e)

$$
50 \mathrm{~s} \text {, (f) } 200 \mathrm{~s}
$$

The thermal histories of some marked points in the cladded layer are shown in Fig. 14. The points P1, P2, and P3 in Fig. 14(a) are located at the molten pool, and their peak temperatures are $1712.31{ }^{\circ} \mathrm{C}$, $1685.27^{\circ} \mathrm{C}$, and $1593.55^{\circ} \mathrm{C}$, respectively. The maximum temperatures at $\mathrm{P} 1$ and $\mathrm{P} 2$ are close to each other. However, the peak temperature at P3 is around $100{ }^{\circ} \mathrm{C}$ lower than at P1 and P2. This decrease could be 
attributed to the distribution of laser energy. As illustrated in Fig. 3, laser intensity is the same for P1 and P2. However, laser intensity at P3 is lower compared to P1 and P2, which led to the decrease of peak temperature at $\mathrm{P} 3$. At $\mathrm{P} 4$, the peak temperature is only about $1273.44{ }^{\circ} \mathrm{C}$. This temperature is lower than the melting point of AISI 420 but higher than the austenization temperature. Therefore, $\mathrm{P} 4$ was located in the HAZ. At P5, the peak temperature is about $695.72{ }^{\circ} \mathrm{C}$. Thus, no phase transformation happened at this position. Moreover, it can be concluded from Fig. 14(a) that points P4 and P5 reach their peak temperatures earlier than points in the cladded layer (P1, P2, and P3). P4 and P5 were located at the substrate and were heated by conduction before the laser beam reached their positions. However, points P1, P2, and P3 were located in the clad and became active after the laser beam reached their positions. Therefore, points in the substrate and HAZ reached peak temperatures earlier than points in the clad.

The temperature histories of the other four marked points along the center of the cross section are shown in Fig. 14(b). As illustrated in the Fig. 14(b), the times for these four points to reach the peak value are different. Moreover, the peak temperature increases first then decreases with the increase of the distance from the top surface to the molten pool. This phenomenon indicated that the peak temperature along the cross section existed in the middle of the molten pool rather than at the top surface. In order to explain this phenomenon, the locations of points 6 through 9 are shown schematically from the side view in Fig. 15 . Initially, points 6 through 9 were inactive. Then, they were activated in sequence with the evolution of the free surface. As a result, the time for these points to reach peak temperatures varied. Moreover, laser intensity had a Gaussian distribution at the side view, and the maximum laser intensity was at the center. Therefore, the middle point of the free surface had the highest peak temperature due to its exposure to the highest laser intensity. As illustrated clearly in Fig. 15, point P7 is located in the middle of the free surface, leading to the highest peak temperature at this point.
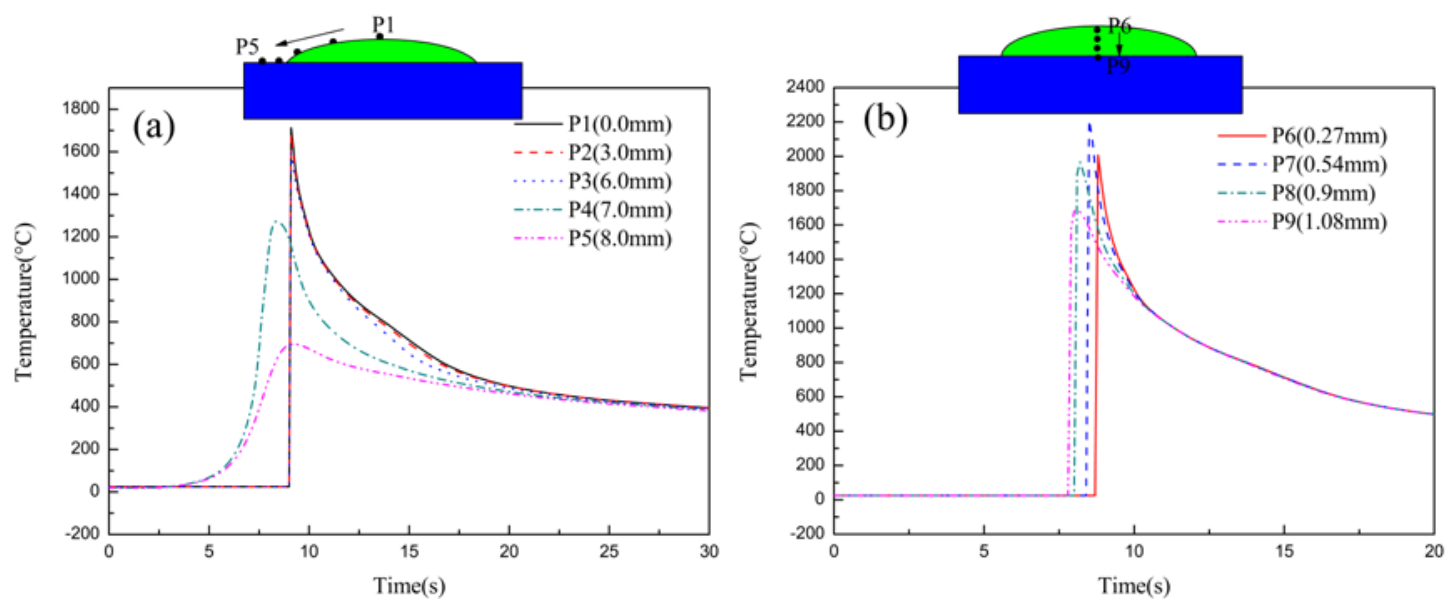

Fig. 14 Thermal cycles of different points: (a) Top surface (b) Center of cross section 


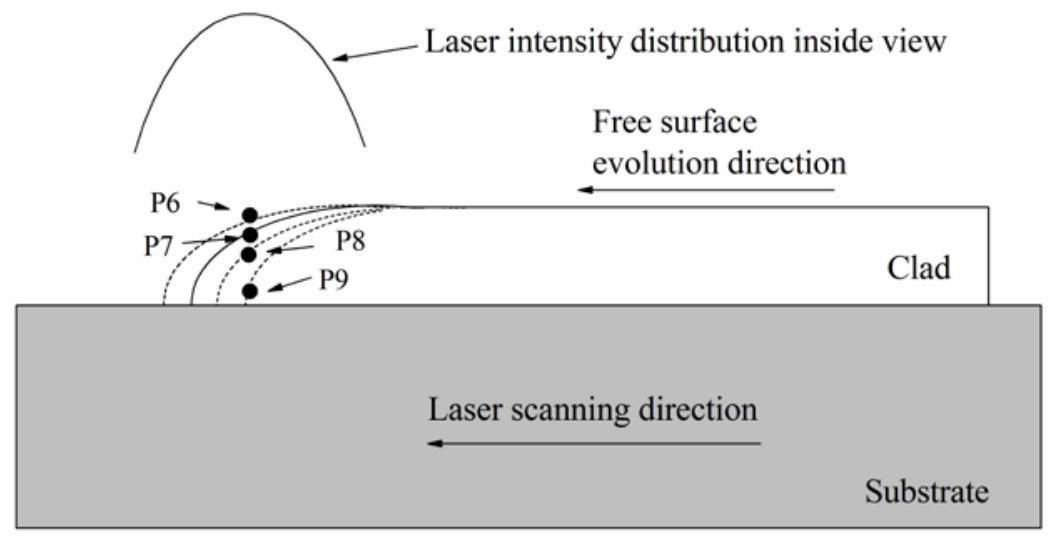

Fig. 15 Schematic points distribution in side view

\subsection{Temperature Gradient and Solidification Rate}

The temperature gradient $\mathrm{G}$ and solidification rate $\mathrm{R}$ are two important parameters that influence the microstructure and properties of the cladding layer such as grain size, grain morphology, and microhardness [4]. The morphology of the grains after solidification changes in sequence from planar, to cellular, cellular dendrite, and columnar dendrite, and then to equiaxed dendrite as the ratio of $\mathrm{R} / \mathrm{G}$ is increasing. The value of $G^{*} R$ determines the grain size. The higher the value of $G^{*} R$, the finer the grain size. The calculation equations of $\mathrm{G}$ and $\mathrm{R}$ are shown in Eq. (16) and Eq. (17), respectively [28].

$$
G=\sqrt{G_{x}^{2}+G_{y}^{2}+G_{z}^{2}}
$$

where $G_{x}, G_{y}$, and $G_{z}$ are the components of $G$ in the x, y, and z directions.

$$
R=V \cos \theta
$$

Where $V$ is the scanning speed of the laser beam. $\theta$ is the angle between the normal of solid-liquid interface, and traveling direction (see Fig. 16(a)). $\cos \theta$ is calculated according to Eq. (18).

$$
\cos \theta=G_{z} / \sqrt{G_{x}^{2}+G_{y}^{2}+G_{z}^{2}}
$$

The values of G, R, and $G^{*} R$ under different scanning speeds along the solid-liquid line are shown in Fig. 16. The values of $G, R$, and $G^{*} R$ are reflected by the colors of the nodes. It can be seen from Fig. 16(b) that the maximum $\mathrm{G}$ is located at the front of the molten pool. As illustrated in Figs. 4 and 14, the maximum laser intensity is distributed at the front of the molten pool, indicating a higher heat input in this region. The front of the molten pool was near the substrate so the heat dissipation was greater. Therefore, a higher $\mathrm{G}$ was observed in the region nearest the high heat input. With the increase in the distance from the front of the molten pool, $\mathrm{G}$ was decreasing. By comparing the different scanning speeds, it could be concluded that $\mathrm{G}$ increased with an increase in scanning speed. At the lower scanning speed, more heat was absorbed by the substrate, and a larger molten pool was produced with a high temperature. Therefore, the temperature change rate along the solid-liquid line varied slowly at the lower scanning speed, and led to a lower temperature gradient compared to the higher scanning speed.

Fig. 16(c) illustrates the distribution of $\mathrm{R}$ along the solidification line. The value of $\mathrm{R}$ distributed inversely compared with the temperature gradient. The maximum value of $\mathrm{R}$ existed at the rear of the 
molten pool, while the minimum value appeared at the front of the molten pool. By increasing the scanning speed, the value of $\mathrm{R}$ was increased due to the decrease in heat input. Moreover, it could be found that the value of $\mathrm{R}$ at the rear of the molten pool was close to the magnitude of the scanning speed. At the same time, the solidification rate approached 0 at the front of the molten pool. According to Eq. (17), the value of $\mathrm{R}$ is determined by the angle $\theta$ at a constant scanning speed. At the front of the molten pool, $\mathrm{R}$ was close to 0 because the angle between normal to the boundary and the scanning speed direction was equal to $90^{\circ}$. However, that angle became $0^{\circ}$ at the rear of the molten pool, which led to the value of $\mathrm{R}$ as it approached the magnitude of the scanning speed.

The products of the $G^{*} R$ (cooling rate) along the solidification line are shown in Fig. 16(d). As shown in Fig. 16(d), the maximum cooling rate is at the rear of the molten pool boundary, while the minimum value appears at the front of the molten pool. Moreover, the cooling rate was increased with an increase in scanning speed.
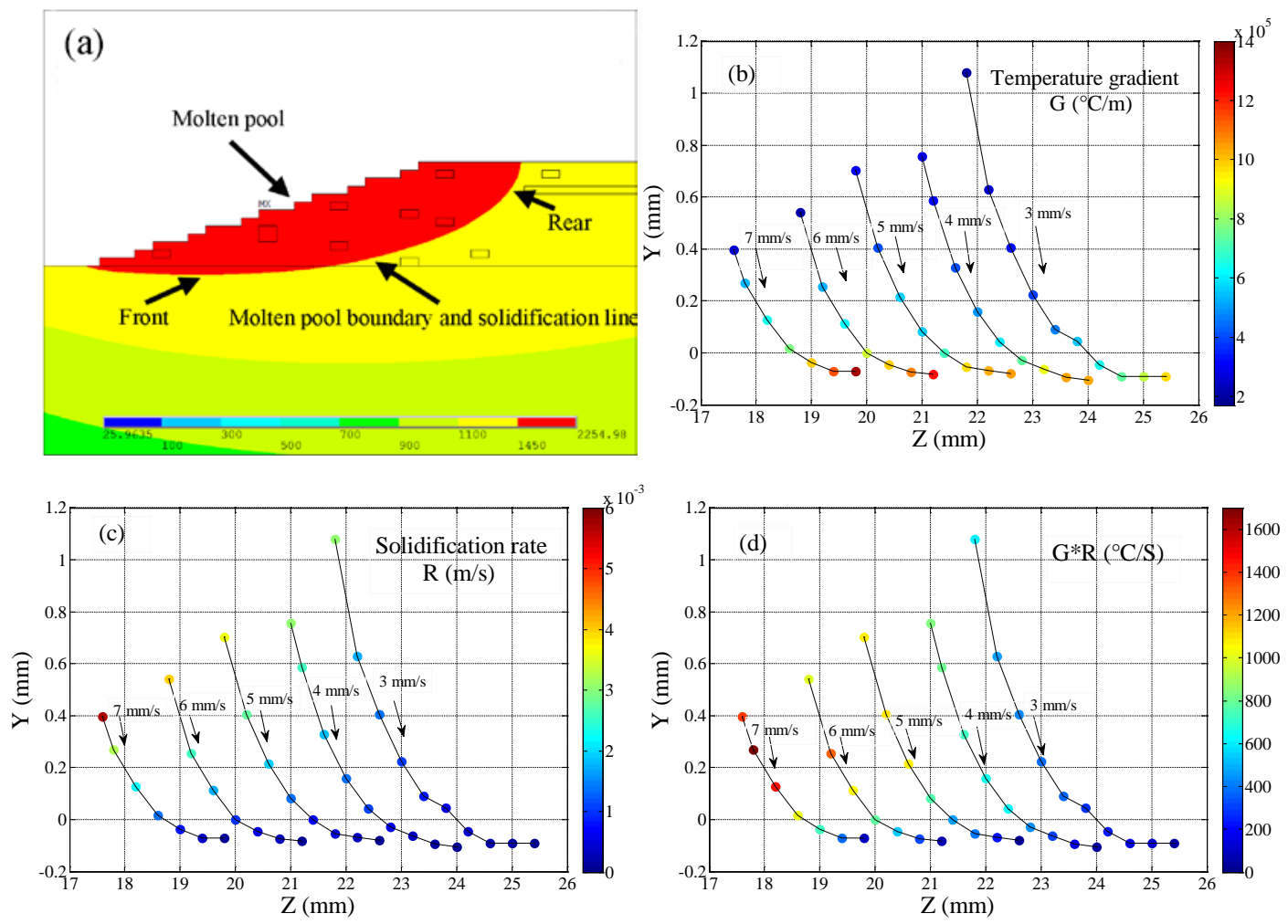

Fig. 16 The distribution of G, R, and G*R, (a) Schematic of the molten pool boundary, (b) G, (c)

$$
\mathbf{R} \text {, and (d) } \mathbf{G} * \mathbf{R}
$$

\subsection{Microstructure}

The microstructures that correspond to the three different scanning speeds are shown in Fig. 16. As illustrated in Fig. 17(a), the planar structure is presented at the interface, demonstrating the formation of metallurgical bonding between the cladded layer and substrate. With the increase in the distance from the interface, the cellular and columnar structures are observed in the cladding layer. As stated previously, the solidification morphology was determined by the ratio of R/G. At the bottom of the clad, a higher value of $\mathrm{G}$ and a lower value of $\mathrm{R}$ are observed (see Fig. 16), leading to a lower value of the R/G ratio. Therefore, planar and cellular microstructures are generated at the bottom of the clad. When it came to the upper 
region of the clad, $\mathrm{R}$ was increasing while $\mathrm{G}$ was decreasing, resulting in the increase in the $\mathrm{R} / \mathrm{G}$ ratio. Thus, columnar structures appear in this region. Fig. 17(b) shows the top surface microstructure with a scanning speed of $3 \mathrm{~mm} / \mathrm{s}$. As indicated by Fig. 17(b), finer dendrites are presented. At the top surface, the cooling rate $\left(\mathrm{G}^{*} \mathrm{R}\right)$ was higher compared to the rate at the interface, leading to a finer microstructure.

The microstructure morphology along the cross-section of the clads under the scanning speed of 5 $\mathrm{mm} / \mathrm{s}$ and $7 \mathrm{~mm} / \mathrm{s}$ are shown in Figs. 17(c, e), respectively. As indicated by the figures, a similar solidification microstructure is observed. The morphology of the microstructure was changing from planar, cellular, and columnar to fine grains from the bottom to the top of the clad. The microstructures at the bottom region of the clads with the scanning speeds of $5 \mathrm{~mm} / \mathrm{s}$ and $7 \mathrm{~mm} / \mathrm{s}$ are shown in Figs. 17(d, f), respectively. As illustrated in the figures, thick planar structure is formed at the interface between the clad and substrate. However, the thickness of the planar structure was decreased from $27.7 \mu \mathrm{m}$ to $13.4 \mu \mathrm{m}$ and $11.5 \mu \mathrm{m}$ when the scanning speed was increased from $3 \mathrm{~mm} / \mathrm{s}$ to $5 \mathrm{~mm} / \mathrm{s}$ and $7 \mathrm{~mm} / \mathrm{s}$. Moreover, the grain size was decreased with the increase in scanning speed. This could be attributed to the fact that the increase in scanning speed led to a decrease in heat input, followed by an increase in cooling rate $\left(\mathrm{G}^{*} \mathrm{R}\right)$. Therefore, a thinner (finer) microstructure was formed at the higher scanning speed.
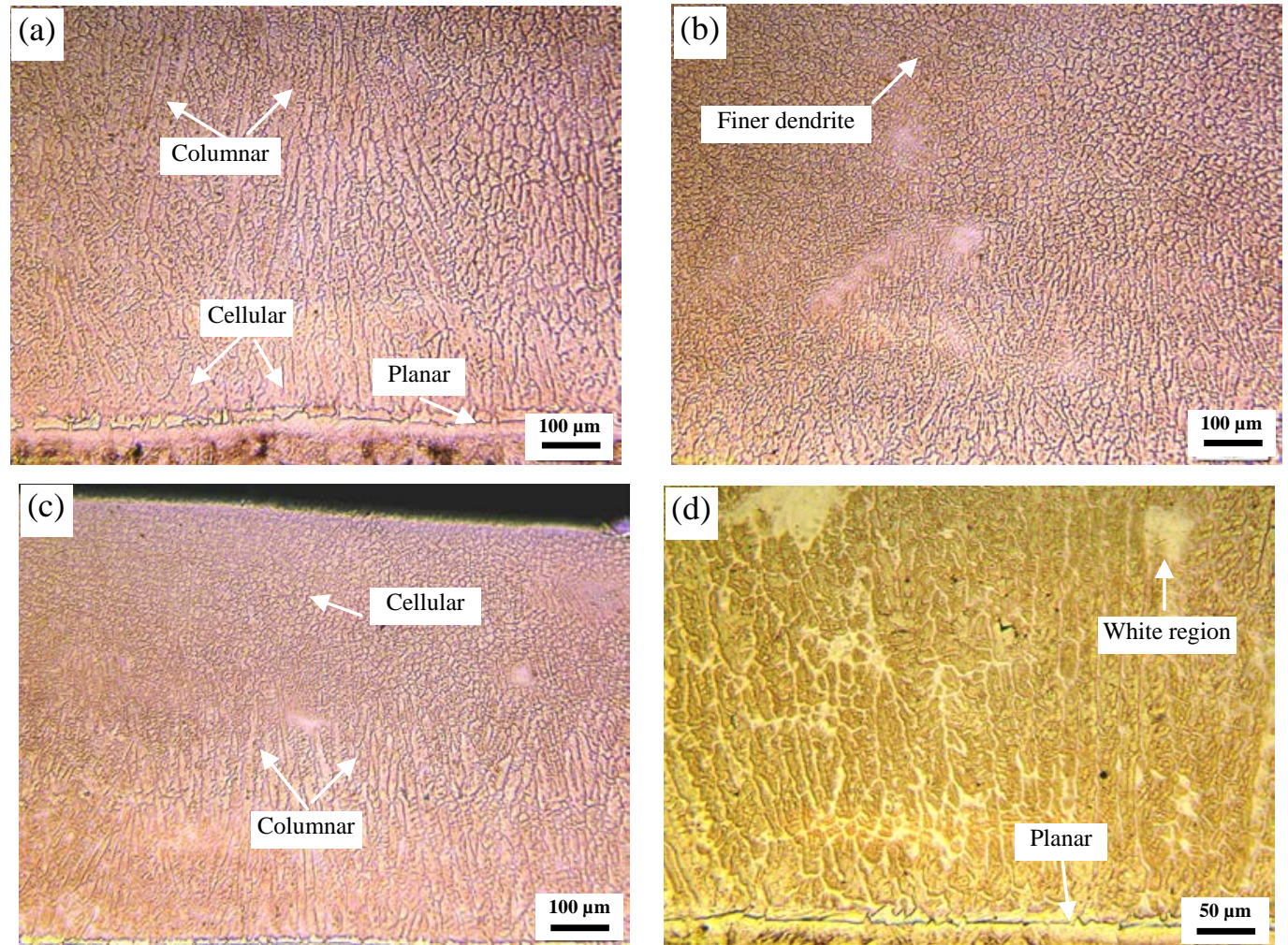

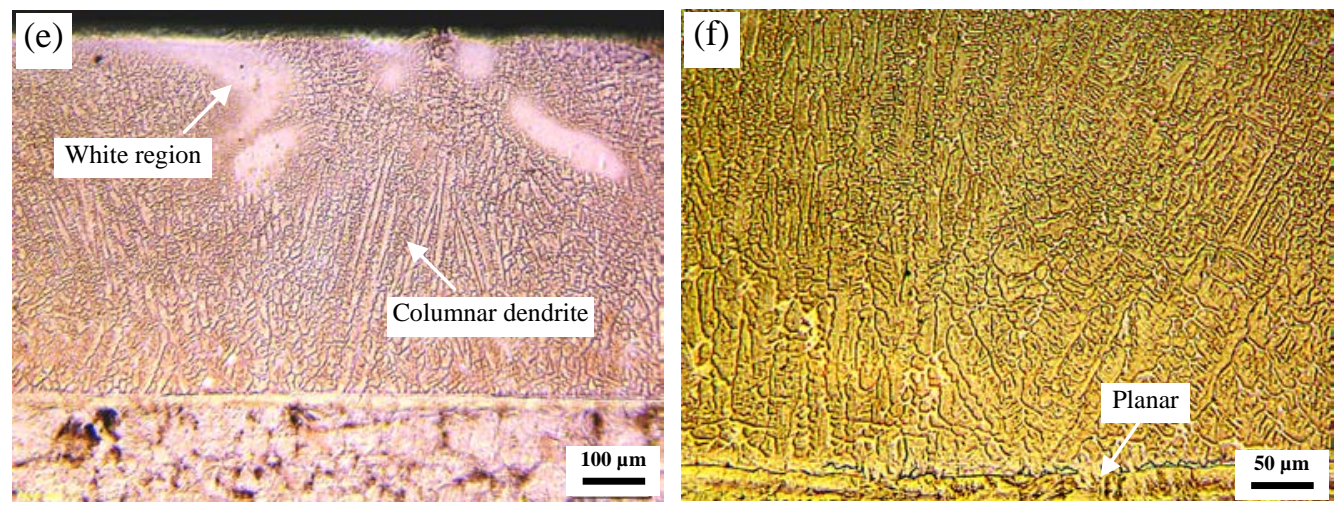

Fig. 17 Microstructure (a) $3 \mathrm{~mm} / \mathrm{s}$ (bottom) (b) $3 \mathrm{~mm} / \mathrm{s}$ (top) (c) $5 \mathrm{~mm} / \mathrm{s}$ (cross section) (d) $5 \mathrm{~mm} / \mathrm{s}$ (bottom) (e) $7 \mathrm{~mm} / \mathrm{s}$ (cross section) (f) $7 \mathrm{~mm} / \mathrm{s}$ (bottom)

As shown in Fig. 17(d), there are a number of white islands distributed through the clad layer. In order to understand these regions, the SEM and EDS tests were carried out on the white island region. Fig. 18(a) shows the backscattering image of the white island in the cladded layer. The EDS line scanning results are shown in Fig. 18(b). It can be concluded from Fig. 18(b) that the white island region corresponds to the region rich with Mo. The EDS spot test shows that the Mo fraction at the center of the white island reaches 32.09 wt.\% while only 1.93 wt.\% Mo is detected at the region outside of the white island (see Fig. 18(a)). Based on the simulation results, the peak temperature during cladding was $2240{ }^{\circ} \mathrm{C}(4100 \mathrm{~W}$ and $3 \mathrm{~mm} / \mathrm{s})$ and was lower than the melting point of Mo $\left(2623{ }^{\circ} \mathrm{C}\right)$. Thus, Mo was dissolved rather than melted during the cladding process. Also, the high cooling rate during the cladding process left insufficient time for the Mo to diffuse. Finally, the regions rich with Mo were formed in the clad layer.
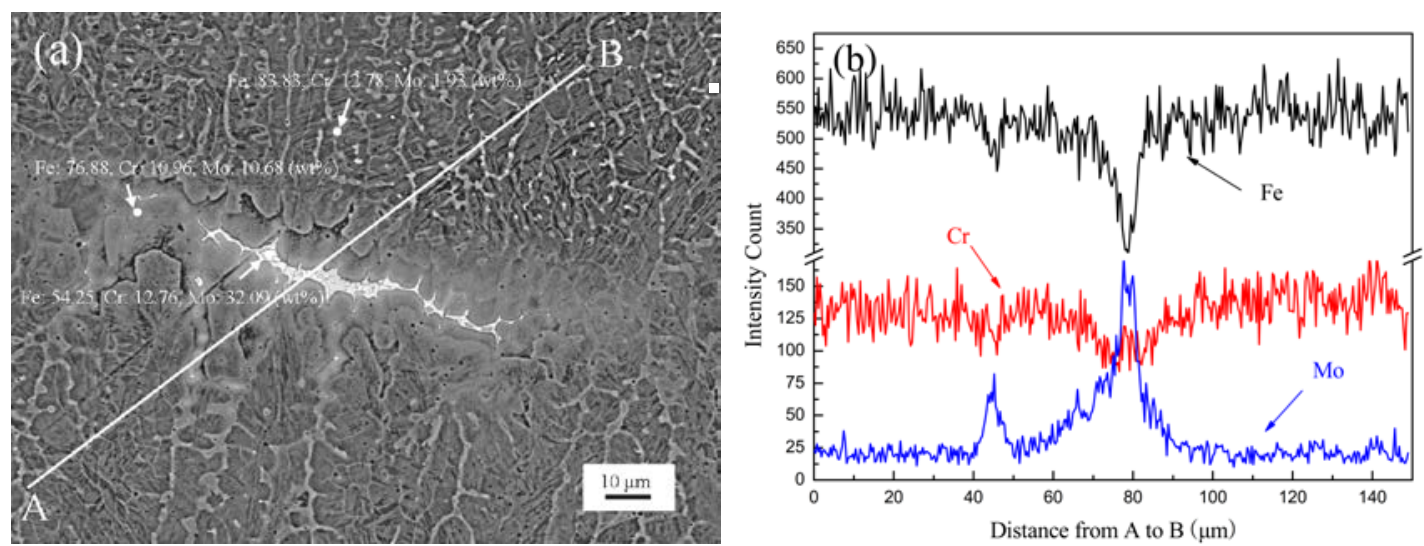

Fig. 18 White island region (a) Backscatter image (b) Line scanning EDS results (4100 W and 7 $\mathbf{m m} / \mathbf{s})$

Fig. 19 shows the percentage of the Mo rich region and the amount of Mo in the clad layer under different scanning speeds. As illustrated in Fig. 19, the content of Mo in the clad is decreasing with the increase in scanning speed. The percentage of the Mo rich region was also increasing with the increase in scanning speed. The decreased scanning speed resulted in the increase of laser energy absorbed by the molten pool and prolonged the time that the molten pool existed. Thus, a higher temperature and longer time were provided for Mo to diffuse. As a result, more Mo was caught by the molten pool, and the number of Mo rich regions was decreased. Moreover, it can be concluded from Fig. 19 that the Mo distributes more 
uniformly through the clad layer at a lower scanning speed. This result could be attributed to the higher energy input at lower scanning speeds leading to the enhancement of the Marangoni convection.

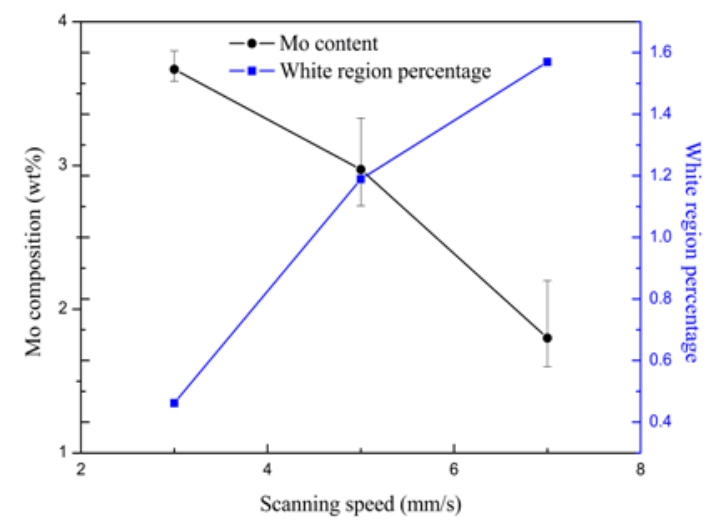

Fig. 19 Mo content and Mo gathered region under different scanning speeds

The SEM micrographs of the cladded layers with different scanning speeds are shown in Fig. 20. As seen from Fig.20, there are three different types of microstructures: the inner grain region, the grain boundary, and the island-shaped region. The number of island-shaped regions is decreasing with the increase in scanning speed. The EDS analysis was done on different regions in order to differentiate them (Table 2). It can be concluded from Table 2 that the island region contains higher $\mathrm{Cr}$ and $\mathrm{Mo}$ compared to the inner grain region.

The transformation sequence of the AISI 420 SS [29] is derived as follows.

$$
L \rightarrow L+\delta \rightarrow \delta+\gamma \rightarrow \gamma \rightarrow M
$$

Generally, delta ferrite is formed during solidification first. With decreasing temperature, the delta ferrite transforms into a fully austenitic structure. Then the austenite transforms to martensite with further cooling. However, due to the high percentage of $\mathrm{Cr}$ in the $420 \mathrm{SS}$ and the addition of Mo, these two ferrite formation elements are partitioned along the grain boundaries at the end of the solidification process, promoting the formation of ferrite through eutectic reaction. Due to the high percentage of ferrite-promoting elements in these regions and the fast cooling rate of the laser cladding process, there is insufficient time for the ferrite to transform into austenite. Thus, ferrite and martensite are formed at room temperature. Based on the SEM and EDS results, the island-shaped microstructures were located at the grain boundaries with a higher percentage of $\mathrm{Cr}$ and Mo. Therefore, the island shaped-region represented ferrite, and the inner grain region represented martensite. Furthermore, as illustrated in Fig. 20, the ferrite percentage is decreasing with the increase in scanning speed due to the decrease in the percentage of Mo in the cladded layer. 

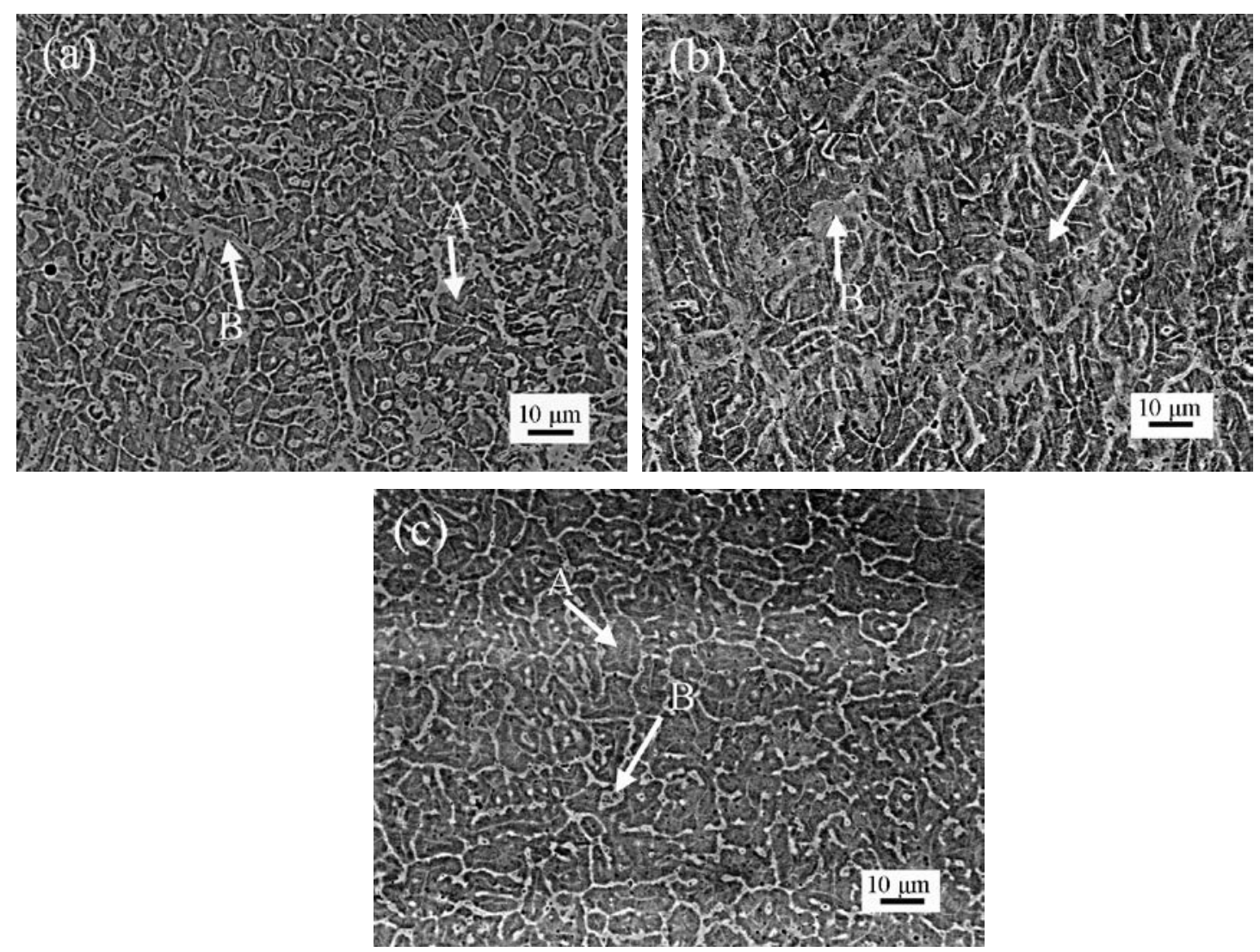

Fig. 20 SEM Micrograph of the cladded layer (a) $3 \mathrm{~mm} / \mathrm{s}$ (b) $5 \mathrm{~mm} / \mathrm{s}$ (c) $7 \mathrm{~mm} / \mathrm{s}$

Table 2 Element distribution in different region

\begin{tabular}{ccccccc}
\hline \multicolumn{2}{c}{ Scanning speed $\mathrm{mm} / \mathrm{s}$} & $\mathrm{Cr}$ & $\mathrm{Mo}$ & $\mathrm{Si}$ & $\mathrm{Mn}$ & $\mathrm{Fe}$ \\
\hline \multirow{2}{*}{3} & A & 13.07 & 3.32 & 0.888 & 0.47 & 82.26 \\
& $\mathrm{~B}$ & 14.53 & 4.47 & 0.93 & 0.38 & 79.68 \\
\multirow{2}{*}{5} & $\mathrm{~A}$ & 12.57 & 2.73 & 0.71 & 0.52 & 83.47 \\
& B & 14.30 & 4.76 & 1.01 & 0.71 & 79.22 \\
7 & A & 13.09 & 0.74 & 1.03 & 0.54 & 84.61 \\
& B & 14.52 & 1.94 & 1.16 & 0.48 & 81.90 \\
\hline
\end{tabular}

\section{Conclusions}

In this study, a 3D FEM model was developed to study the heat transfer process of laser cladding of AISI $420+4 \%$ Mo on mild steel A36. An analytical model was developed to consider the effect of laser beam and powder interaction. The experiments were carried out using an 8-kW HPDDL laser based station to verify the simulation results. Based on the present study, several points could be concluded.

(1) The laser power attenuation model that was used showed a $1 \%$ reduction in laser power under the selected parameters. The powder was heated up by the laser beam before it reached the molten pool. The maximum powder temperature was $172.1{ }^{\circ} \mathrm{C}$ while only $62.3{ }^{\circ} \mathrm{C}$ was calculated at the boundary of the molten pool.

(2) Based on the strategy of continuously stacking thin layers of melting powder in the molten pool, clad geometrical characteristics were obtained. The predicted geometry of the clads showed a good agreement with the experimental ones. 
(3) The maximum temperature gradient $G$ was found at the bottom of the molten pool while the minimum value was located at the top surface of the clad. An inverse relationship between the temperature gradient $\mathrm{G}$ and solidification rate $\mathrm{R}$ was found. The maximum $\mathrm{R}$ was found at the top of the clads with a value approaching the scanning speed. Whereas, the minimum $R$ is at bottom of the clads with a value close to 0 . The increase of the scanning speed led to the increase of $G$ and $R$.

(4) The microstructure morphology of the cladded layer changed from cellular to columnar and finer dendrites going from the bottom to the top surface of the clad. With an increase in scanning speed, the percentage of Mo in the clad layer was decreasing, while the number of regions with a higher concentration of Mo was increasing. The microstructures of the clad layer at room temperature were martensite and ferrite. Ferrite was distributed at the grain and sub-grain boundaries. The percentage of ferrite was decreased with the increase in scanning speed.

\section{Acknowledgements}

This work was financially support by the NSF's Grant no. IIP-1539853. The authors also would like to thank the research engineer, Andrew Socha, in the Center for Laser-aided Manufacturing, for his help in the execution of experiments.

\section{Reference}

[1] F. Weng, H. Yu, C. Chen, J. Dai, Microstructures and wear properties of laser cladding Co-based composite coatings on Ti-6Al-4V, Mater. Des. 80 (2015) 174-181.

[2] D. Verdi, M. A. Garrido, C. J. Múnez, P. Poza, Cr3C2 incorporation into an Inconel 625 laser cladded coating: Effects on matrix microstructure, mechanical properties and local scratch resistance, Mater. Des. 67 (2015) 20-27.

[3] L. Li, The advances and characteristics of high-power diode laser materials processing, Opt. Laser Eng. 34 (2000) 231-253.

[4] H. Zhu, M. Hao, J. Zhang, W. Ji, X. Lin, J. Zhang, Y. Ning, Development and thermal management of 10kW CW, direct diode laser source. Opt. Laser Technol. 76 (2016) 101-105.

[5] Z. Weng, A. Wang, Y. Wang, D. Xiong, H. Tang, Diode laser cladding of Fe-based alloy on ductile cast iron and related interfacial behavior, Surf. Coat. Technol. 286 (2016) 64-71.

[6] L. Costa, R. Vilar, T. Reti, A. M. Deus, Rapid tooling by laser powder deposition: Process simulation using finite element analysis. Acta Mater. 53 (2005) 3987-3999.

[7] S. Santhanakrishnan, F. Kong, R. Kovacevic, An experimentally based thermo-kinetic hardening model for high power direct diode laser cladding, J. Mater. Process. Technol. 211 (2011) 1247-1259.

[8] P. Farahmand, R. Kovacevic, An experimental-numerical investigation of heat distribution and stress field in single-and multi-track laser cladding by a high-power direct diode laser, Opt. Laser Technol. 63 (2014) 154-168.

[9] E. Toyserkani, A. Khajepour, S. Corbin, Three-dimensional finite element modeling of laser cladding by powder injection: effects of powder feedrate and travel speed on the process, J. Laser Appl. 15 (2003) 153-160.

[10] E. Toyserkani, A. Khajepour, S. Corbin, 3-D finite element modeling of laser cladding by powder injection: effects of laser pulse shaping on the process, Opt. Laser Eng. 41 (2004) 849-867.

[11] V. Fallah, M. Alimardani, S. F. Corbin, A. Khajepour, Temporal development of melt-pool morphology and clad geometry in laser powder deposition, Comput. Mater. Sci. 50 (2011) 2124-2134.

[12] P. Peyre, P. Aubry, R. Fabbro, R. Neveu, A. Longuet, Analytical and numerical modelling of the direct metal deposition laser process, J. Phys. D: Appl. Phys. 41 (2008) 025403.

[13] I. Tabernero, A. Lamikiz, E. Ukar, S. Martínez, A. Celaya, Modeling of the geometry built-up by coaxial laser material deposition process. Int. J. Adv. Manuf. Tech. 70 (2014) 843-851.

[14] A. J. Pinkerton, An analytical model of beam attenuation and powder heating during coaxial laser direct metal deposition, J. Phys. D: Appl. Phys. 40 (2007) 7323.

[15] S. Wen, Y. C. Shin, Modelling of the off-axis high power diode laser cladding process, J. Heat Transfer, 
133 (2011) 031007.

[16] S. Liu, P. Farahmand, R. Kovacevic, Optical monitoring of high power direct diode laser cladding, Opt. Laser Technol. 64 (2014) 363-376.

[17] Y. Chew, J. H. L. Pang, G. Bi, B. Song, Thermo-mechanical model for simulating laser cladding induced residual stresses with single and multiple clad beads, J. Mater. Process. Technol. 224 (2015) $89-101$.

[18] X. He, G. Yu, J. Mazumder, Temperature and composition profile during double-track laser cladding of H13 tool steel, J. Phys. D: Appl. Phys. 43 (2010), 015502.

[19] P. Balu, S. Hamid, R. Kovacevic, Finite element modeling of heat transfer in single and multilayered deposits of Ni-WC produced by the laser-based powder deposition process. Int. J. Adv. Manuf. Tech. 68 (2013) 85-98.

[20] P. J. Karditsas, M. J. Baptiste, Molybdenum and its alloys. http://www-ferp.ucsd.edu/LIB/PROPS/PANOS/moa.html, 1995.

[21] S. Nadimi, R. J. Khoushehmehr, B. Rohani, A. Mostafapour, Investigation and analysis of weld induced residual stresses in two dissimilar pipes by finite element modeling, J. Appl. Sci. 8 (2008) 1014-20.

[22] SYSWELD 2015 Material database, ESI Group, 2015.

[23] M. Alimardani, E. Toyserkani, J. P. Huissoon, A 3D dynamic numerical approach for temperature and thermal stress distributions in multilayer laser solid freeform fabrication process, Opt. Laser Eng. 45 (2007) $1115-1130$

[24] W. I. Cho, S. J. Na, C. Thomy, F. Vollertsen, Numerical simulation of molten pool dynamics in high power disk laser welding, J. Mater. Process. Technol. 212 (2012) 262-275.

[25] A. Kumar, C. P. Paul, A. K. Pathak, P. Bhargava, L. M. Kukreja, A finer modeling approach for numerically predicting single track geometry in two dimensions during Laser Rapid Manufacturing. Opt. Laser Technol. 44 (2012) 555-565.

[26] A. M. Kamara, W. Wang, S. Marimuthu, L. Li, Modelling of the melt pool geometry in the laser deposition of nickel alloys using the anisotropic enhanced thermal conductivity approach, Proc. Inst. Mech. Eng., Part B 225 (2011) 87-99.

[27] K. Shah, I. ul Haq, A. Khan, S. A. Shah, M. Khan, A. J. Pinkerton, Parametric study of development of Inconel-steel functionally graded materials by laser direct metal deposition, Mater. Des. 54 (2014) 531-538. [28] Y. Lee, M. Nordin, S. S. Babu, D. F. Farson, Effect of Fluid Convection on Dendrite Arm Spacing in Laser Deposition, Metall. Mater. Trans. B 45 (2014) 1520-1529.

[29] Z. Zhang, R. Kovacevic, Multiresponse Optimization of Laser Cladding Steel + VC Using Grey Relational Analysis in the Taguchi Method, JOM (2016) 1-12. 


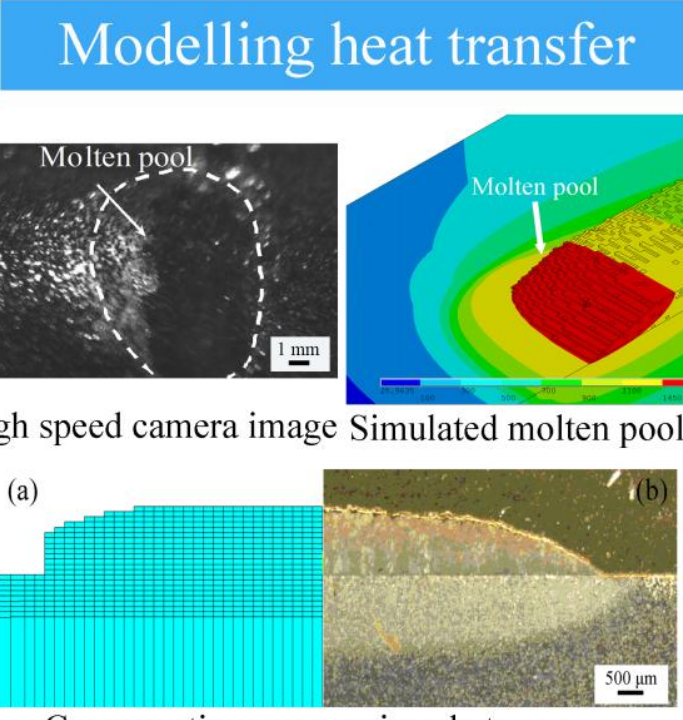

Cross-sections comparison between

(a) simulation and (b) experimental results
Analysis of the thermal results

Study of the microstructure
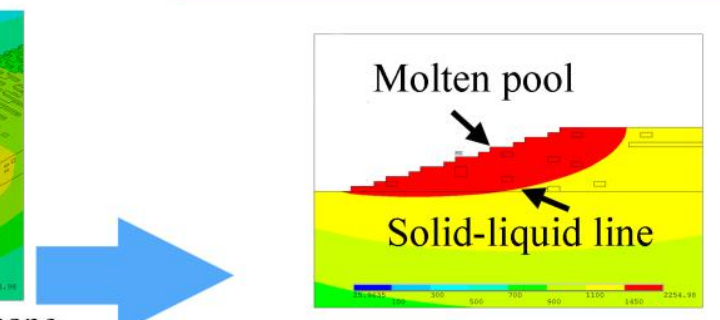

Solidification boundary
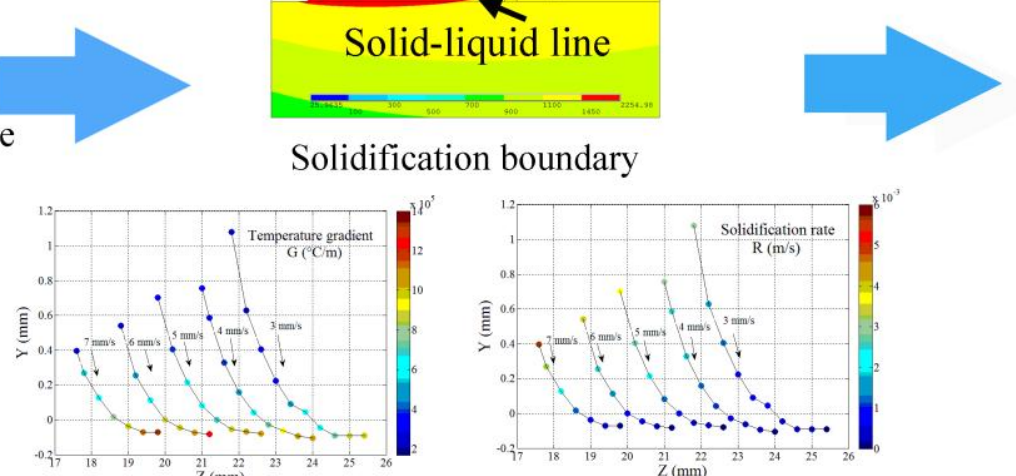

Temperature gradient

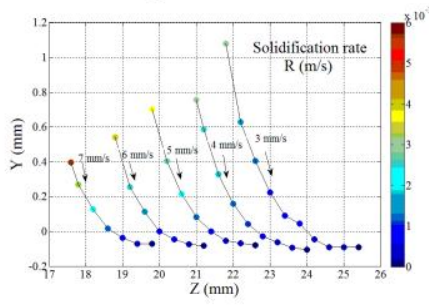

Solidification rate

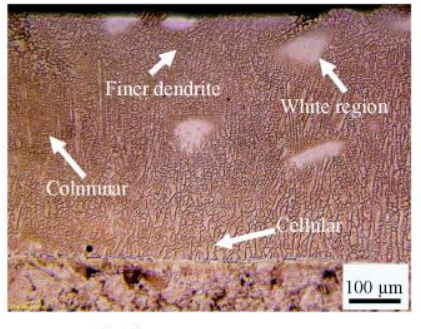

Microstructure

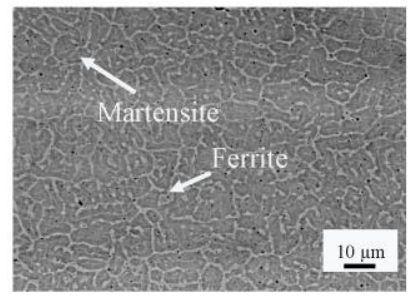

SEM image 